\title{
A informação documentária: codificação e decodificação
}

\author{
The documentary information: coding and decoding
}

Vânia Mara Alves LIMA'

\section{RESUMO}

Procuramos demonstrar como a classificação do conhecimento científico, ao longo dos séculos, tem se refletido na organização deste conhecimento e na elaboração da informação documentária nas instituições responsáveis pela sua preservação e disseminação. Sustentamos a suposição demonstrando o seu valor explicativo, por meio da análise da tensão dialética que se estabelece entre os sistemas de classificação e os sistemas de recuperação, tensão essa que determina o processo semiótico denominado representação documentária, e possibilita as enunciações de codificação e de decodificação da informação documentária. Concluímos, recomendando que o desenvolvimento e gerenciamento de linguagens documentárias levem em conta a dinâmica da enunciação de codificação e da enunciação de decodificação da informação documentária.

Palavras-chave: informação documentária; terminologia; linguagem documentária.

\section{A B S T R A C T}

In this article we demonstrate that the classification of the scientific knowledge, throughout the centuries, has been reflected in the organization of such knowledge and in the elaboration of the documentary information in institutions which have been responsible for its preservation and dissemination. We support this assertion and demonstrate its clarifying value through the analysis of the dialectic tension that establishes itself between the systems of classification and the retrieval systems. Such tension determines the semiotic process called documentary representation, and makes possible both, coding and decoding enunciations of the documentary information. Concluding, we recommend that the development and management of documentary languages should take into account the dynamics of coding and decoding enunciations of the documentary information.

Keywords: documentary information; terminology; documentary languages.

\section{NTRODUÇÃ O}

A construção de novos conhecimentos e, conseqüentemente, o desenvolvimento da sociedade depende da recuperação dos conhecimentos produzidos anteriormente. Por sua vez, a recuperação desses conhecimentos é considerada adequada e efetiva quando o conteúdo informacional dos documentos é explícito pela informação documentária elaborada em um Sistema de Informação.
Partindo dessa premissa procuramos explicitar os processos semióticos envolvidos na elaboração de uma informação documentária capaz de representar os conteúdos informacionais de qualquer tipo de documento, independente de seu suporte.

A elaboração da informação documentária é determinada pela tensão dialética que se estabelece entre os Sistemas de Classificação - sejam eles linguagens documentárias tradicionais, como a Classificação Decimal de Dewey (CDD), a Classificação Decimal

\footnotetext{
1 Professora, Departamento de Biblioteconomia e Documentação, Escola de Comunicações e Artes, Universidade de São Paulo. Av. Prof. Lúcio Martins Rodrigues, 443, Cidade Universitária, 05508-900, São Paulo, SP, Brasil. E-mail: <vamal@usp.br>.

Recebido em 28/11/2006 e aceito para publicação 22/5/2007.
} 
Universal (CDU), ou, os modernos tesauros construídos a partir das terminologias das áreas - e os Sistemas de Recuperação de Informação, acessados pelos usuários de um Sistema de Informação.

Essa tensão dialética permeia as etapas de construção e recuperação da informação documentária e envolve os mesmos processos semióticos presentes no percurso lingüístico e comunicacional que Pais (1993, p.535-541; 1994, p. 164) denominou como percurso gerativo da enunciação de codificação e da enunciação de decodificação.

Ao identificar as etapas desse percurso, ao qual nos referimos aqui como enunciação de codificação e enunciação de decodificação da informação documentária, identificamos as dificuldades encontradas pelas linguagens documentárias para representar a informação. Essas dificuldades por sua vez, nos levam a propor que sejam considerados, no desenvolvimento, manutenção e gerenciamento de novas linguagens documentárias, os vários aspectos envolvidos nesse percurso.

\section{A classificação do conhecimento e a recuperação da informação}

A sociedade busca perpetuar e transmitir seus valores e seu conhecimento para as suas sucessivas gerações, mas essa transmissão só é possível quando esse conhecimento é registrado, organizado e pode ser recuperado.

Buscar princípios para uma classificação ideal, capaz de promover a ordenação e recuperação das obras produzidas pela sociedade, tem sido tarefa historicamente delegada à Biblioteconomia.

Um sistema de classificação pode ser baseado em fundamentos filosóficos, teológicos ou práticos, mas tem sempre como objetivo primordial organizar o conhecimento de modo que ele seja passível de recuperação e uso pelos leitores (Rafferty, 2001). Portanto, ao classificar os livros, a biblioteca reflete a classificação do conhecimento produzido pela sociedade na qual está inserida. Durante séculos, as estantes e prateleiras das bibliotecas eram organizadas de acordo com a classificação do conhecimento realizada pelas cátedras nas universidades e essa organização, por sua vez, refletia-se na classificação bibliográfica.
No final do século XIX, Charles Cutter transformou as relações entre os catálogos e os livros, propondo um "catálogo dicionário", o qual passaria a reunir no mesmo fichário, os nomes dos autores, títulos, assuntos e o tipo de literatura. Essa proposta possibilita o surgimento de novos sistemas de classificação como a Classificação Decimal de Dewey (CDD), a Classificação Decimal Universal (CDU), a Classificação da Biblioteca do Congresso (LC), a Classificação de Dois Pontos e, mais contemporaneamente, os Tesauros. Dentre todos esses novos sistemas de classificação, são os tesauros que vão difundir o termo linguagem documentária como instrumento que tem por objetivo controlar os termos utilizados na representação do conhecimento.

Formulado segundo princípios lógico-semânticos, o tesauro é um vocabulário estruturado segundo um léxico hierarquizado de acordo com as relações semânticas entre os termos utilizados, denominados descritores, e os não utilizados, denominados nãodescritores, os quais contribuem para o exercício da representação. Ao converter os conceitos e suas relações, expressas em linguagem natural, para uma linguagem controlada, o tesauro demonstra que a informação tem sua existência atrelada aos sistemas de significação e que é necessário operar-se no âmbito desse universo de sistemas para a identificação, análise, tratamento e disseminação da informação.

Segundo Tálamo; Lara; Kobashi (1992, p. 197) atualmente a construção dos tesauros não está fundamentada apenas na categorização do conhecimento em assuntos, herança dos tradicionais sistemas de classificação com suas estruturas prescritivas e hierárquicas, mas também, no corpus discursivo do qual são retirados os termos considerados significativos.

Assim, o tesauro, ao categorizar o conhecimento em assuntos, pretende garantir a organização do universo objeto de representação e; ao selecionar os conceitos mais freqüentes para representação da informação, garantir a contigüidade e semelhança entre o vocabulário a ser utilizado para representação e o universo do conhecimento expresso em textos. Desta maneira, o tesauro permite que a área que está sendo indexada, constitua um todo significativo.

As atuais diretrizes de elaboração de tesauros prescrevem a identificação de relações de natureza hierárquica, associativa e de equivalência entre os termos, relações estas que provêem o arranjo necessário 
a uma proposta de organização do conhecimento. Entretanto, tais diretrizes não dizem como encontrar as referências para sedimentar o processo de identificação e de relacionamento entre os termos.

Conforme Lara (2002, p.134), para que os tesauros sejam estruturas significantes, seus termos devem remeter aos conceitos de um domínio. A delimitação de conceitos e termos não é uma operação simples, e remete a princípios teóricos e metodológicos específicos que são objeto da disciplina Terminologia.

A teoria terminológica permite operacionalizar o recorte de um domínio e, em seguida, organizar esse domínio de forma a que ele se constitua em uma estrutura significante. Dessa maneira, a Terminologia, enquanto disciplina, subsidia o trabalho documentário.

De fato, a Terminologia procura garantir a comunicação especializada pelo acompanhamento da prática científica, incorporando e normalizando os novos conceitos gerados pelo domínio científico, que são designados pelos termos. A linguagem documentária, por sua vez, procura garantir a representação e a recuperação da informação, gerada pelo novo conhecimento, através da fabricação da informação documentária.

A terminologia concreta (os termos) é a base para a estruturação do conhecimento nas linguagens de especialidade e deve servir de referente para os descritores das linguagens documentárias, pois ao realizar a articulação do conceito com o termo, permite construir a informação documentária.

Portanto, o papel das terminologias na representação do conhecimento é primordial, pois segundo Benveniste (1989, p.252), uma ciência só começa a existir, ou consegue se impor, na medida em que faz existir e em que impõe seus conceitos através de sua denominação. Isto, porque tal ciência não tem outro meio de estabelecer sua legitimidade senão por especificar seu objeto denominando-o, podendo este constituir uma ordem de fenômenos, um domínio novo ou um modo novo de relação entre certos dados. Denominar é, ao mesmo tempo, a primeira e última operação de uma ciência.

A informação documentária pode ser entendida como um signo, denominado signo documentário, em analogia ao signo lingüístico da linguagem natural (Lara, 1993, p.97). Portanto, partindo da análise do signo lingüístico realizada por Blikstein (1983), inferimos que a informação documentária seria a representação dos conteúdos informacionais dos documentos, através de seu conceito/significado, utilizando como referente/ objeto o conjunto de termos da terminologia de uma área do conhecimento (Lima, 2004, p. 1 19), conforme a Figura 1:

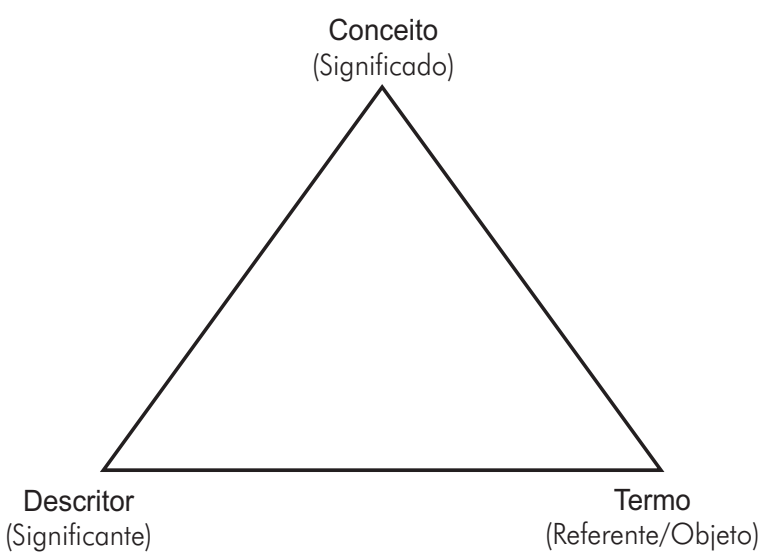

Figura 1. Informação documentária (Lima, 2004, p.119).

É a partir deste modelo que esquematizamos o processo da enunciação de codificação e enunciação de decodificação da informação documentária.

\section{O percurso gerativo da enunciação de codificação e da enunciação de decodificação}

Consideramos que o processo da enunciação de codificação e da enunciação de decodificação da informação documentária é análogo ao percurso gerativo da enunciação de codificação e da enunciação de decodificação apresentado por Pais (1993, p.535-541 ; 1994, p. 164), este percurso, além de possibilitar o engendramento das unidades lexicais - que ocorre segundo a dinâmica do sistema semiótico lingüístico e que, quando de sua atualização em discurso, conduz à produção de significação e de informação novas - também pode ser considerado como um ciclo de tratamento, pois vai da conceptualização à lexemização, da lexemização à produção discursiva da significação e da informação e, destas últimas, à armazenagem e à recuperação da informação, de maneira a desencadear um novo mecanismo de conceptualização.

Segundo Pais (1993, p.524), os processos semióticos que ocorrem no interior dos sistemas se- 
mióticos e de seus discursos, são considerados processos de produção fundados em relações de significação e, na semiose permanente, permitem produzir significação e informação, isto é, possibilitam a produção, transferência, armazenamento e recuperação da informação. Conforme Pais (1994, p. 166), são os sistemas semióticos que asseguram a continuidade de determinada comunidade e the permitem reconhecer-se sempre como idêntica a si mesma, não obstante as constantes mudanças. Isto ocorre porque os sistemas de significação só funcionam de modo satisfatório na medida em que se estabelece uma tensão dialética entre duas forças contrárias, a da conservação, que assegura o entendimento entre os sujeitos, e a da mutação, que satisfaz as necessidades de mudança da sociedade. Conforme Figura 2:

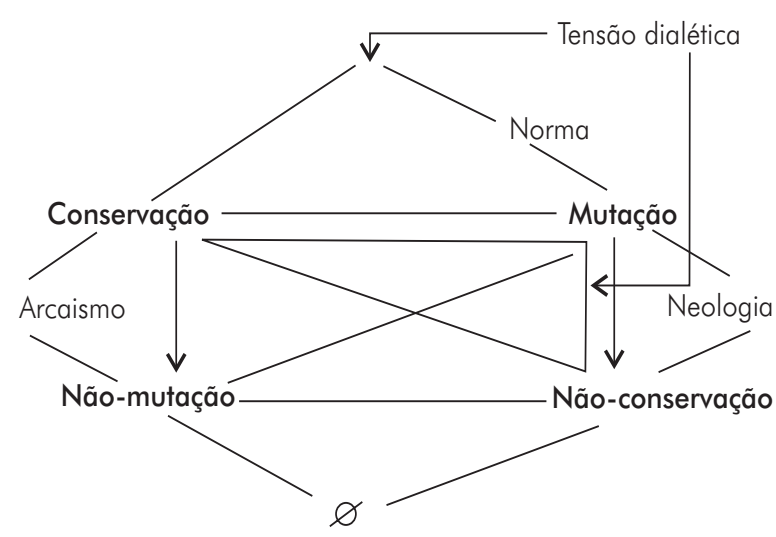

Figura 2. Sistema.

Fonte: (Pais, 1993 apud Lima, 2004, p. 124).

Por outro lado, como as novas significações não podem ser produzidas em nível do sistema, mas somente no percurso sintagmático dos discursos, toda análise nova de um objeto, de um evento, ou de um atributo (traço de objeto e de processo) deve, de um lado, realizar-se em termos que assegurem a intercompreensão dos sujeitos e, de outro lado, oferecer elementos de uma experiência específica, a fim de atribuir um valor de comunicação ao discurso manifestado. Disso resulta a tensão dialética que se apóia nas duas tendências contrárias, o consenso e a especi$\sum_{3}^{\pi}$ ficidade, cujo equilíbrio dinâmico assegura a produtividade do discurso (Pais, 1993, p.528; 1994, p. 166), como ilustra a Figura 3:

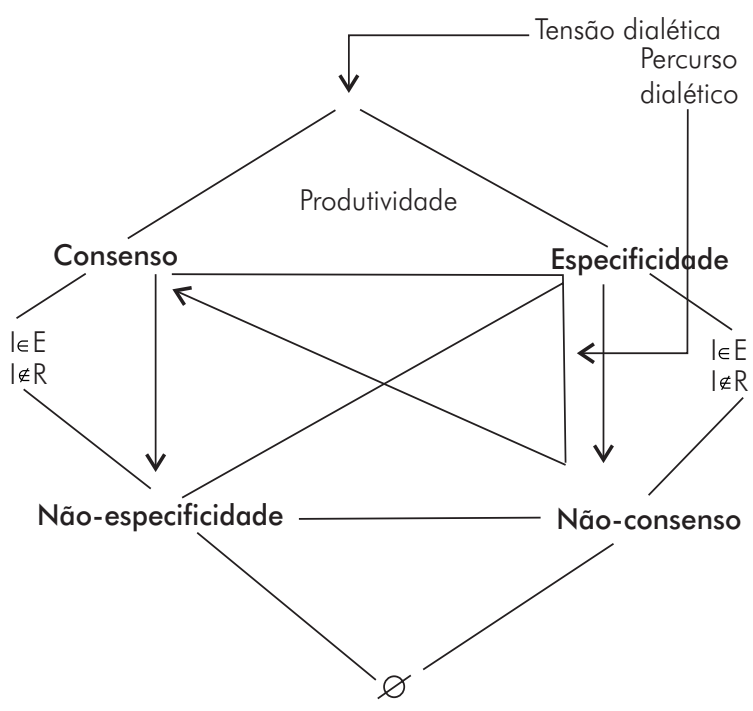

Figura 3. Discurso.

Fonte: (Pais, 1993 apud Lima, 2004, p. 126).

Ainda segundo Pais (1993, p.530), a tensão dialética sistema/discurso define o processo semiótico enquanto processo de produção. Aqui o sistema, concebido como a competência, que em um dado momento produz um discurso, dá início a um processo de enunciação. Este discurso, baseado na tensão consenso/ especificidade, produz uma parte de significação nova e de informação nova a partir de elementos que não pertenciam originariamente ao sistema. Assim, ainda que o discurso reitere tanto as significações como as informações produzidas por discursos anteriores, ele produz e reconstrói por si mesmo um segmento da visão de mundo.

Parte da significação e da informação produzida em discurso, é recuperada pelo sistema e armazenada na memória dos usuários. Essas significações e esses recortes podem ser utilizados na produção de discursos subseqüentes. Assim, uma tensão sistema/discurso se define, cujo dinamismo contribui para sustentar a permanência e o funcionamento do processo semiótico (Pais, 1994, p. 167).

De acordo com Pais (1993, p.530-531), no processo semiótico e informacional, a combinação sistema $x$ não-discurso define a competência. Esta assegura o entendimento entre os sujeitos a partir da conservação e do consenso (lingüístico ou semiótico) estável entre os interlocutores em função dos discursos anteriores. Já a combinação discurso x não-sistema caracteriza a performance, que reúne a mutação e a especificidade das novas significações e das novas informações. A combinação sistema $x$ discurso, por 
sua vez, corresponde à tensão dialética em que se apóia o processo semiótico. Ao mesmo tempo, define a produção discursiva e agrega ao sistema novas significações e informações. Dito de outro modo, o sistema produz o discurso e o discurso produz o sistema, segundo representado na Figura 4:

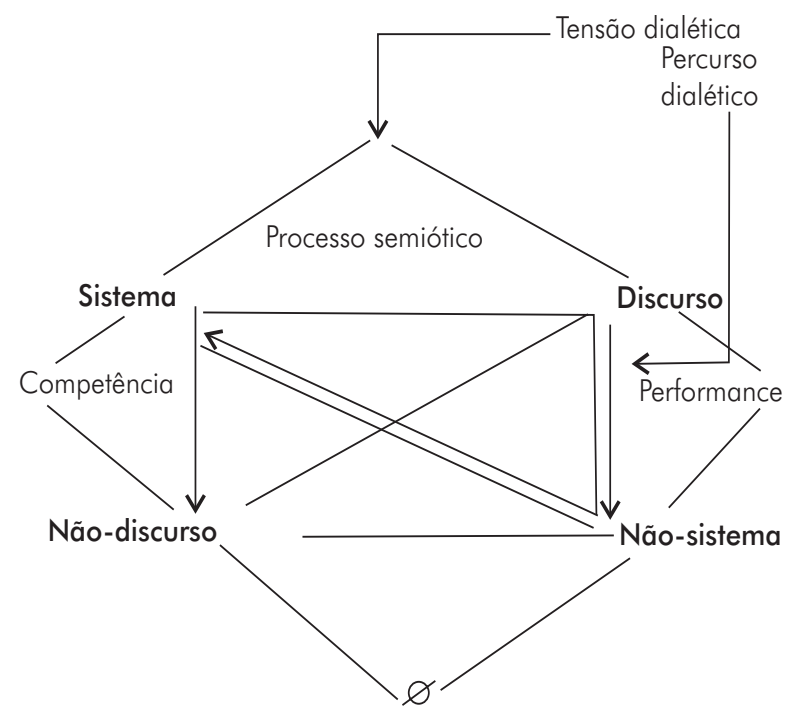

Figura 4. Processo semiótico e informacional. Fonte: (Pais, 1993 apud Lima, 2004, p. 128).

Percurso gerativo da enunciação de codificação

Percepção (objetos do mundo)

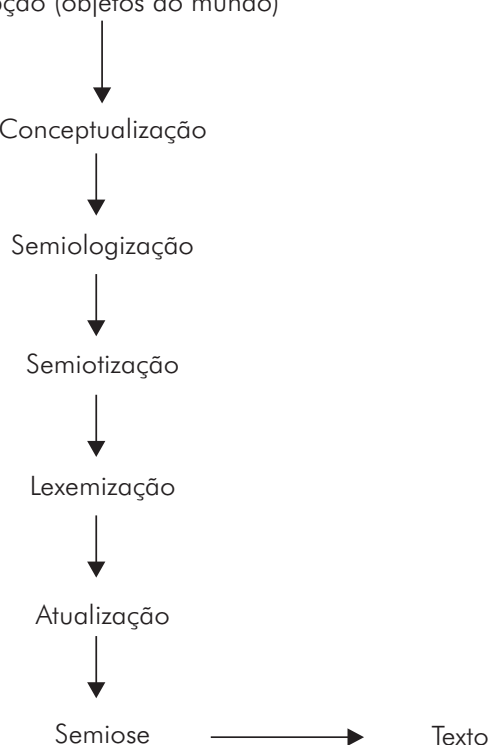

A partir dos modelos de Pottier e de Greimas, 123 Pais (1997, p.224) desenvolve um modelo próprio de percurso gerativo da enunciação de codificação e da enunciação de decodificação. Este percurso, em sua totalidade, considera os patamares da percepção, da conceptualização, da semiologização, incluindo também a semiotização, a lexemização, a atualização e a semiose, quanto ao fazer persuasivo e, quanto ao fazer interpretativo, considera os patamares do reconhecimento, da re-semiotização, da ressemiologização e da reconceptualização, além das transformações que se realizam entre tais patamares. $\bigcirc$ percurso, em sua totalidade, aparece esquematizado na Figura 5.

Barbosa (2001, p.34) inclui o nível terminológico, no percurso gerativo das enunciações de codificação e decodificação, pois é na instância discursiva que se produz a cognição e a semiose, se instaura a conceptualização de um 'fato', se engendra um conceito e sua manifestação lingüística. Para a autora, junto à lexemização está a terminologização que corresponde à conversão do conceito em grandeza-signo. Portanto, a terminologização completa o percurso gerativo da enunciação de codificação, onde a grandeza-signo,

Percurso gerativo da enunciação de decodificação

Realimentação do Metassistema conceptual

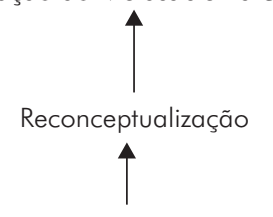

Ressemiologiazação

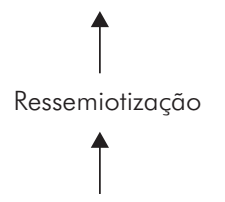

Re-leximização

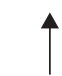

Reatualização

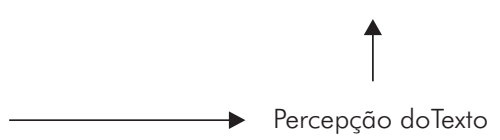

Figura 5. Percurso gerativo.

Fonte: (Pais, 1997 apud Lima, 2004, p.132). 
convertida em termo, passa a ser utilizada em um discurso concretamente realizado em determinada área do conhecimento.

Analogamente, observamos que o sistema de classificação também sustenta-se na tensão dialética entre a conservação - pois é construído a partir de sistemas de classificações precedentes, que mantêm o status quo, disseminando a ideologia dominante, através de decisões sobre a instituição a que pertencem, suas classes principais, suas subdivisões e a ordem das coisas - e a mutação, não só as resultantes de novas significações e de novas informações, mas também a resultante da introdução das novas tecnologias que, ao sublinharem seu caráter mais pragmático, exigem uma determinação conceptual cada vez mais rigorosa e a definição cada vez mais fina de uma linguagem documentária que possibilite a recuperação da informação.

Da mesma maneira, também o sistema de recuperação da informação se sustenta na tensão dialética entre o consenso, que deve ser estável entre os interlocutores em função dos discursos anteriores e de suas relações de intersubjetividade, e a especificidade, configurada pelos elementos novos, ou seja, informação nova e significação nova.

Assim, podemos inferir que a Ciência da Informação sustenta-se nas tensões dialéticas presentes nesses dois sistemas, tensões as quais sustentam uma terceira tensão dialética, mais ampla, que se estabelece entre o sistema de classificação e o sistema de recuperação, entre o sistema e o discurso, e que sustenta diretamente, por um lado, no sistema de classificação, a competência relacionada ao conhecimento, e de outro, no sistema de recuperação da informação, sustenta a performance, possibilitada pela informação documentária.

Portanto, inferimos que o processo semiótico que ocorre entre o sistema de classificação e o sistema de recuperação da informação é o da representação documentária, a qual subsume as tensões dialéticas que ocorrem entre: conservação/mutação; consenso/especificidade, sistema/discurso, e que permitem descrever as relações entre o conhecimento e a informação documentária, ilustrado na Figura 6:

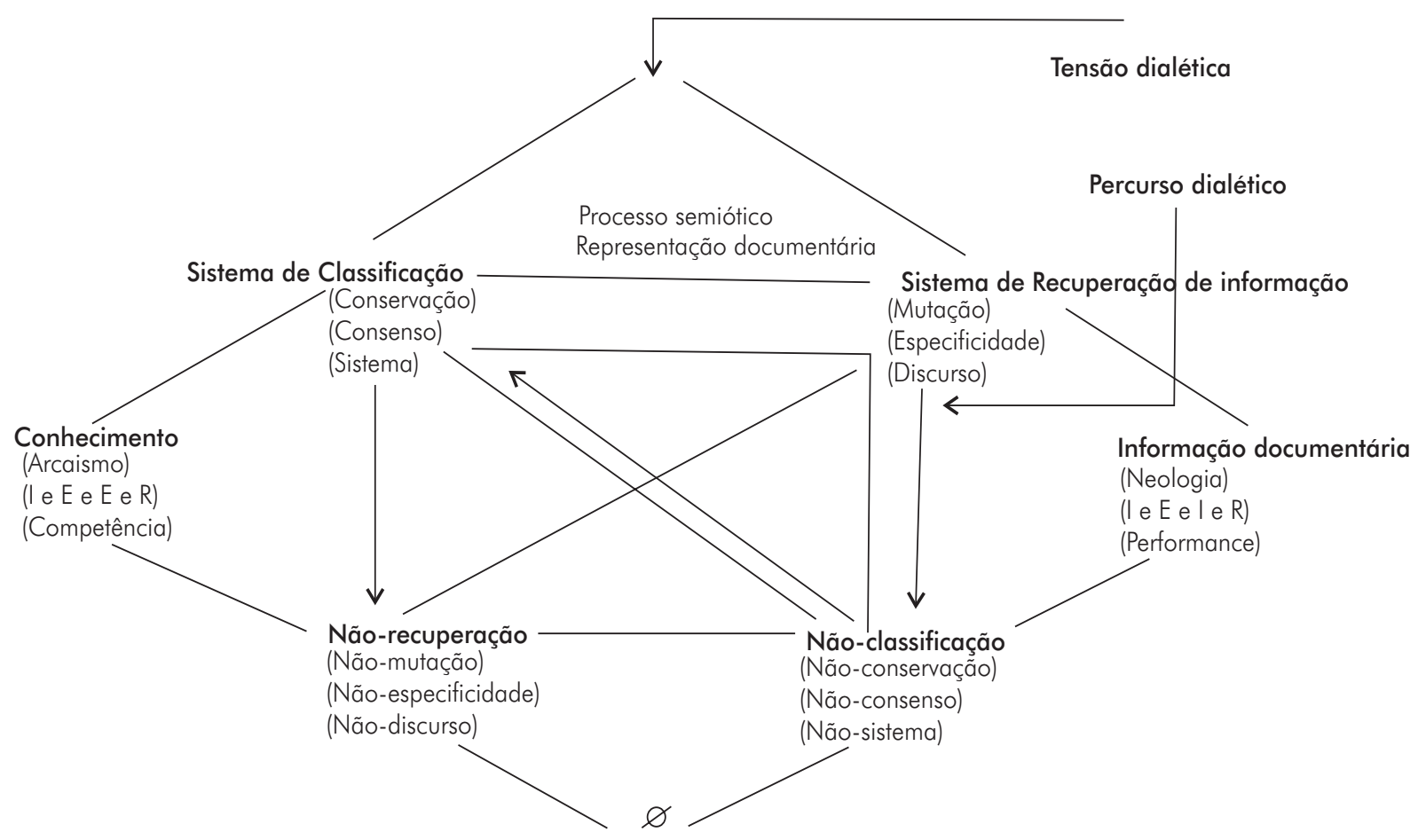

Figura 6. Sistema de Classificação/Recuperação

Fonte: (Lima, 2004, p. 136).

TransInformação, Campinas, 19(2): 119-127, maio/ago., 2007 
A enunciação de codificação e a enunciação de decodificação da informação documentária

Segundo Lara (1993, p.64-65), a principal característica da informação documentária convencional é o seu caráter generalizante, pois os conceitos, idéias e fatos presentes no texto original são colocados em classes categoriais, visando a facilitar seu reconhecimento posterior. Esta perda de referenciais concretos pode ser minimizada quando o profissional encarregado desta tarefa é um especialista de área, portanto, capaz de reconhecer a arquitetura conceitual do domínio em questão e de identificar e interpretar ocorrências típicas da sua linguagem técnico-científica. Como essa condição nem sempre é satisfeita, é necessária a existência de um código comutador, isto é, de uma linguagem documentária consistente, para realizar a codificação do conteúdo do texto, em informação documentária.

As linguagens documentárias constituem sistemas de significação que têm por função específica normalizar os conceitos de área, controlar seu uso $\mathrm{e}$ viabilizar a comunicação entre um sistema de informação e o usuário.

Da mesma maneira que a linguagem natural, uma linguagem documentária apresenta um plano de expressão e um plano de conteúdo (Hielmslev, apud Lara, 1993, p.66), organizado em função de um paradigma. Uma linguagem documentária é estruturada de acordo com os campos lexicais e semânticos de uma área de conhecimento, mas a ausência de definições que remetam a contextos determinados, ou o uso indevido de suas expressões, comprometem a sua função comunicativa.

Segundo Lara (1993, p.68), esta ausência de definições leva ao predomínio da equivalência lexical, processo que transforma a linguagem documentária em uma nomenclatura, tornando inútil a informação documentária produzida, uma vez que, sob esta forma, uma dada palavra encontrada num texto, pode ser "representada", automaticamente, por palavra semeIhante encontrada na linguagem documentária, alterando-se os vínculos de significação.

Para que isso não ocorra, deve-se delimitar o contexto em que as palavras se inserem, para construir a informação documentária; o que nos leva a considerar, em primeiro lugar, a terminologia enquanto referente para uma linguagem documentária e, conseqüentemente, ao processo de terminologização, isto é, a conversão de um conceito em termo de uma área específica. Tal processo garantirá a função comunicativa de uma linguagem documentária e a possibilidade de enunciação de codificação e enunciação de decodificação da informação documentária.

A partir da tensão dialética entre o sistema de classificação e o sistema de recuperação da informação, o processo de representação documentária, realizado através de uma linguagem documentária, possibilita a construção da informação documentária. Esta construção ocorre com o fazer persuasivo de um enunciador, ou seja: o indexador, a partir de uma concepção orientada pelo conteúdo e pela demanda, realiza a enunciação de codificação da informação documentária.

A enunciação de decodificação da informação documentária só ocorre através do fazer interpretativo do usuário, dentro de um determinado contexto, o qual é delimitado pela terminologia da área de conhecimento.

Assim, a tensão dialética que se instaura entre o sistema de classificação e o sistema de recuperação da informação, como também a enunciação de codificação e a enunciação de decodificação da informação documentária, pode ser esquematizado conforme a Figura 7.

Neste esquema, o processo da enunciação de codificação e da enunciação de decodificação da informação documentária, parte do conceito. Este conceito, após sofrer os processos de percepção, conceptualização, semiologização, semiotização, lexemização e terminologização, será convertido pelo indexador em um termo que, contextualizado, se torna o descritor de uma linguagem documentária. Esta possibilitará, por sua vez, a semiose por parte do usuário e os subseqüentes processos: de percepção da informação documentária, da reatualização ou do reconhecimento, da re-semiotização, da ressemiologização e da reconceptualização.

\section{CONSIDERAÇÕES FINAIS}

Observamos, no decorrer do trabalho, as principais dificuldades encontradas pelas linguagens 


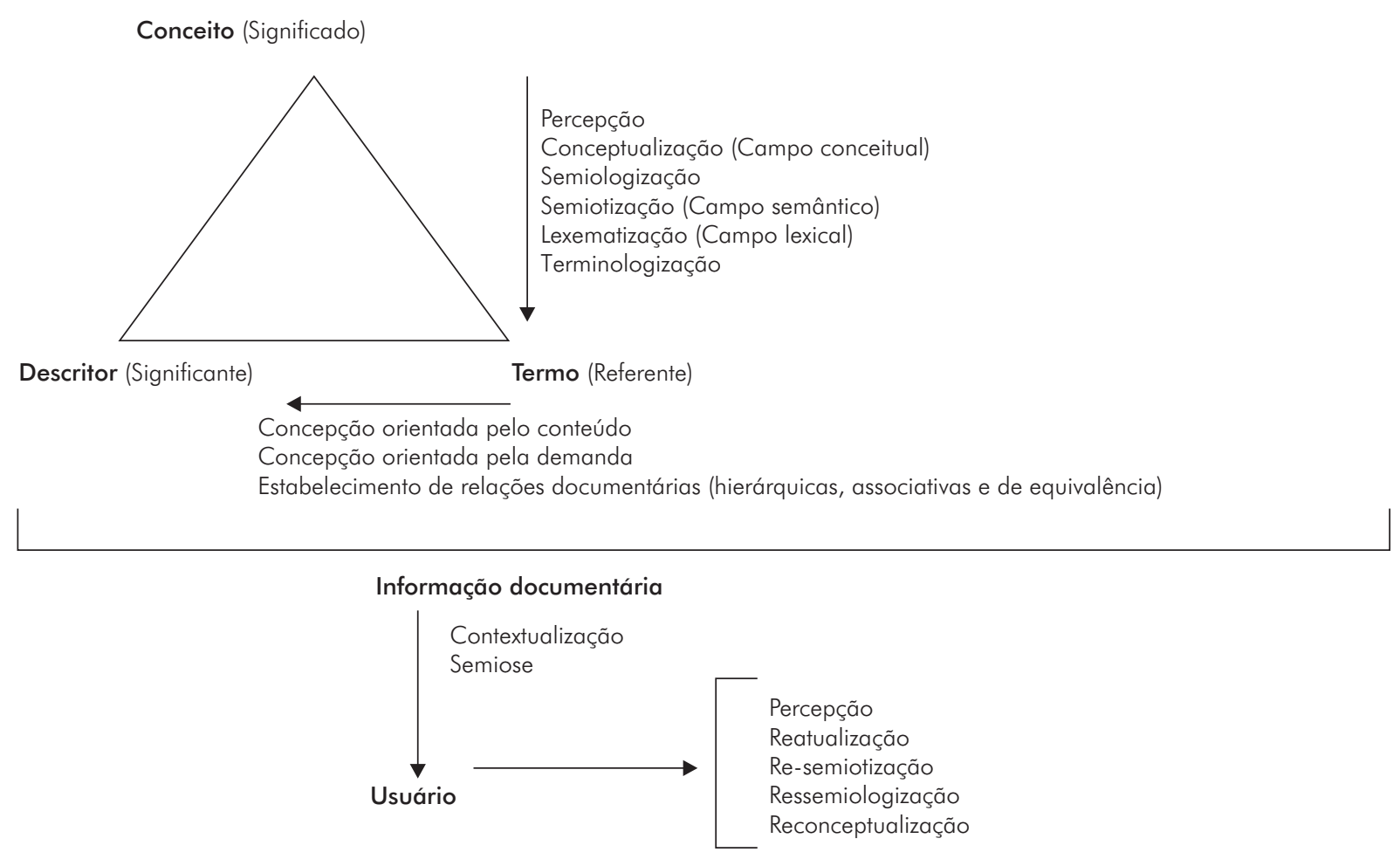

Figura 7. Enunciação de codificação e decodificação da informação documentária (Lima, 2004, p.141).

documentárias no processo de representação documentária. Tais dificuldades são: (1) as linguagens documentárias pretendem reunir os termos pertencentes às linguagens de especialidade, isto é, as terminologias de domínio, as unidades lexicais presentes na linguagem natural utilizada pelos usuários; (2) as linguagens documentárias são construídas para trabalhar com o consenso, solicitado pela sociedade; mas devem, ao mesmo tempo, responder à especificidade presente na solicitação de cada usuário; (3) as linguagens documentárias classificam o conhecimento de acordo com as necessidades da sociedade, mas o fazem conservando o status quo e respondendo muito lentamente ao processo de mutação dessa mesma sociedade; mesmo quando elegem a terminologia como referente para a sua elaboração.

Essas dificuldades aumentam consideravelmente quando as linguagens documentárias trabalham com mais de uma área do conhecimento e, conseqüentemente, com mais de uma terminologia de domínio.

Portanto, a partir das questões abordadas neste trabalho, propomos que sejam observados os seguintes aspectos no desenvolvimento, manutenção e geren- ciamento de novas linguagens documentárias, de forma a possibilitar a enunciação de codificação e a enunciação de decodificação da informação documentária: (a) existe uma tensão dialética permanente entre o sistema de classificação e o sistema de recuperação da informação; (b) a combinação conservação/mutação contempla, simultaneamente a intercompreensão dos sujeitos, mantendo pontos de acesso de sistemas anteriores e possibilita a inclusão de novos pontos de acesso, notadamente aqueles ligados às terminologias de domínio; (c) a combinação consenso/especificidade que assegura o consenso solicitado pela sociedade, também responde à especificidade dos usuários, ao possibilitar as estes a pós-coordenação das informações documentárias no momento da busca; (d) o percurso da enunciação de codificação da informação documentária, partindo de um conceito em determinada área de conhecimento, envolve as etapas da percepção, da conceptualização, da semiologização, da semiotização, da lexematização e da terminologização, estabelecendo-se um termo; (e) a partir da terminologização, o estabelecimento das relações hierárquicas, associativas e de equivalência entre os descritores, 
transforma o termo em um descritor; ( $f$ ) a transformação do termo em descritor advém de concepção orientada para o conteúdo e/ou para a demanda; (g) e por fim, a informação documentária é sempre de natureza contextual.

Em síntese, a classificação do conhecimento científico reflete-se tanto nos sistemas tradicionais de classificação das bibliotecas, como nos modernos tesauros. Como os usuários da informação documentária são, potencialmente, produtores de conhecimento, espera-se que uma linguagem documentária, analogamente à linguagem natural, funcione com um código no processo de comunicação documentária, isto é, entre o objeto no qual o conhecimento está

\section{REFERÊNCIAS}

BARBOSA, M. A. A construção do conceito nos discursos técnico-científicos, nos discursos literários e nos discursos sociais não-literários. Revista Brasileira de Lingüística, v. 1 1 , n. 1, p.31$60,2001$.

BENVENISTE, E. Problemas de lingüística geral - II, Campinas: Pontes, 1989.

BLIKSTEIN, I. Kaspar Hauser ou a fabricação da realidade. São Paulo: Brasiliense, 1983.

LARA, M.L.G. O processo de construção da informação documentária e o processo do conhecimento. Perspectivas em Ciência da Informação, v.7, n.2, p. 127-139, 2002.

LARA, M.L.G. Representação documentária: em jogo a significação. 1993. Dissertação (Mestrado em Ciências da Comunicação) - Escola de Comunicações e Artes, Universidade de São Paulo, São Paulo, 1993.

LIMA, V.M.A. Da classificação do conhecimento científico aos sistemas de recuperação de informação: enunciação de codificação e enunciação de decodificação da informação documentária. 2004. Tese (Doutorado em Ciências da Comu- inscrito, o documento, e aquele que procura a informação, o usuário.

Para que o processo de comunicação documentária seja efetivado satisfatoriamente, isto é, possibilite a recuperação da informação, a linguagem documentária necessita fundamentar-se na terminologia do domínio, pois é ela que promove a articulação entre os conceitos que definem o domínio e os termos que podem designá-los.

Assim, espera-se que a informação documentária, ao ser codificada pelo indexador e decodificada pelo usuário, possibilite o surgimento de novos conhecimentos que colaborem para promover o desenvolvimento social e humano. nicação) - Escola de Comunicações e Artes, Universidade de São Paulo, 2004.

PAIS, C.T. Conceptualização, denominação, designação: relações. Revista Brasileira de Lingüística, v.9, n. 1, p.221-239, 1997.

PAIS, C.T. Conditions sémantico-syntaxiques et sémiotiques de la productivité systémique, lexicale et discursive. Thèse de Doctorat d'Etat ès-Lettres et Sciences Humaines - Paris/Lille, Université de Paris-Sorbonne (Paris-IV), Atelier National de Reproduction des Thèses - Université de Lille III, 1993. 2 t.

PAIS, C.T. Percurso gerativo da enunciação: produtividade léxica e discursiva. Confluência: Boletim do Departamento de Lingǘstica, v.3 , n.esp., p.162-81, 1994.

RAFFERTY, P. The representation of knowledge in library classification schemes. Knowledge Organization, v.28, n.4, p.180-191, 2001.

TÁLAMO, M.F.G.M.; LARA, M.L.G.; KOBASHI, N.Y. Contribuição da terminologia para a elaboração de tesauro. Ciência da Informação, v.21, n.3, p.197-200, 1992. 
